\title{
Dicyphus predatory bugs pre-established on tomato plants reduce Nesidiocoris tenuis population growth
}

\author{
Angelos Mouratidis $^{1,2} \cdot$ Ada Leman $^{1} \cdot$ Erik H. Poelman ${ }^{2} \cdot$ Gerben Messelink $^{1,2} \oplus$
}

Received: 6 August 2021 / Revised: 6 November 2021 / Accepted: 28 January 2022 / Published online: 21 February 2022

(c) The Author(s) 2022

\begin{abstract}
Generalist predators are increasingly used in biological pest control for greenhouse crops, as they control multiple pests and persist in crops even when prey is scarce. However, some of these predators may cause plant damage due to their omnivorous feeding behaviour. In many European regions, the omnivorous predator Nesidiocoris tenuis (Reuter) (Hemiptera: Miridae) is considered to be a serious tomato pest, regardless of the biological control services it offers, and integrated pest management (IPM) strategies are based instead on Macrolophus pygmaeus (Rambur). However, as $N$. tenuis may competitively displace M. pygmaeus and cause severe damage, growers often resort to pesticide use, disrupting their biological control practice. In this study, we evaluated the competitive interactions of three mirid predators, Dicyphus errans Wolff, Dicyphus bolivari Lindberg, and Dicyphus cerastii Wagner, with N. tenuis. The results showed that pre-establishment of heterospecific mirid species can successfully suppress $N$. tenuis in the greenhouse; population growth was reduced by more than $90 \%$ compared to plants without competing predators. Further laboratory trials revealed reciprocal intraguild predation between these species in the absence of extraguild prey. Dicyphus adults predated on $N$. tenuis nymphs, while this was not found for M. pygmaeus. In olfactometer bioassays, $N$. tenuis females preferred plants previously exposed to heterospecifics but not conspecifics, suggesting that this mirid does not avoid competition. These results suggest that the three Dicyphus species could be interesting candidates for preventive releases in tomato crops due to their ability to effectively suppress $N$. tenuis population growth.
\end{abstract}

Keywords Interspecific competition $\cdot$ Intraguild predation $\cdot$ Omnivory $\cdot$ Dicyphini $\cdot$ Miridae $\cdot$ Zoophytophagy

\section{Key message}

- Pre-establishment of Dicyphus predators on tomato crop reduced population growth of $N$. tenuis.

Communicated by Amy Roda .

Gerben Messelink

gerben.messelink@wur.nl

Angelos Mouratidis

angel.mouratidis@wur.nl

Ada Leman

ada.leman@wur.nl

Erik H. Poelman

erik.poelman@wur.nl

1 Wageningen UR Greenhouse Horticulture, P.O. Box 20, Bleiswijk 2265 ZG, Netherlands

2 Wageningen University, Laboratory of Entomology, P.O. Box 16, Wageningen 6700 AA, Netherlands
- Dicyphus adults predated on N. tenuis nymphs, but not in the presence of extraguild prey.

- $\quad$. tenuis females were attracted by plants previously infested by heterospecific mirids.

- Dicyphus predators may be interesting candidates for preventive biological control strategies in tomato crops.

\section{Introduction}

Omnivorous organisms feed on resources from more than one trophic level (Pimm and Lawton 1978). A well-documented example of omnivory is intraguild predation (IGP), a phenomenon in which an omnivorous predator consumes another predator, with which it shares a common herbivore as prey (Rosenheim et al. 1995). Omnivory may extend to feeding on both plants and animal organisms, also known as true omnivory (Coll and Guershon 2002). Thus, the status of true omnivorous arthropods in agriculture can vary. Their primary feeding behaviour places them on the continuum 
between phytozoophagy (prey-feeding herbivores) and zoophytophagy (plant-feeding carnivores) (Coll and Guershon 2002). A well-studied family of omnivorous insects are the mirids (Hemiptera: Miridae). In this family, the phytozoophagous Lygus hesperus (Knight) is a catastrophic pest of several crops, yet it is also an important predator of whiteflies in the cotton agroecosystem (Hagler and Naranjo 2005). Because several zoophytophagous mirid predators are considered effective biocontrol agents, they are also actively mass-reared and released to suppress important agricultural pests (van Lenteren 2012). An interesting consequence of plant feeding by mirids is their ability to induce plant responses, similar to those of strict herbivores (Kessler and Baldwin 2004; Pérez-Hedo et al. 2015). These responses alter the volatile profile of plants, qualitatively and/or quantitatively (Pérez-Hedo et al. 2017). These herbivore-induced plant volatiles (HIPVs) may serve as infochemicals for foraging herbivores, natural enemies, and conspecifics (Moayeri et al. 2007; Lins et al. 2014; Pérez-Hedo et al. 2015; Rim et al. 2018). Thus, insect-plant interactions should also be considered when assessing the use of mirids in biological control programmes (Cuny et al. 2021).

Most debate on the use of omnivorous mirids in biological control focuses on the mirid Nesidiocoris tenuis (Reuter). This species is a widely used biological control agent in the Mediterranean Basin against several key pests, including whiteflies and the South American tomato leafminer (Calvo et al. 2009, 2012; Mollá et al. 2014). The damage that this mirid may occasionally cause on greenhouse crops includes flower abortion and necrotic rings on stems and fruits, yet the damage appears to be outweighed by its biological control services in some Mediterranean regions (Sánchez 2008, 2009; Sánchez and Lacasa 2008; Perdikis et al. 2009; Arnó et al. 2010). In contrast, in Northern Europe, where Macrolophus pygmaeus (Rambur) is the main biological control agent of greenhouse tomato crops (Put et al. 2012), N. tenuis is considered a serious pest of tomato (Trottin-Caudal et al. 2006; Moerkens et al. 2020). The different status of $N$. tenuis in these regions might be due to the different cultivation practices, pest pressure, varieties grown, and damage tolerance (Pérez-Hedo et al. 2021). For example, cherry and truss tomato cultivars are known to be more susceptible to damage by zoophytophagous mirids (Castañé et al. 2011). Many Dutch greenhouses, particularly those that produce tomatoes with artificial light year-round, became unintentionally infested by $N$. tenuis, resulting in serious crop damage (authors' personal observations, unpublished data). Moreover, growers report that $N$. tenuis displaces $M$. pygmaeus over the course of the growing period.

The reasons of this displacement are debated in the literature, and it seems that multiple factors drive these predator-predator interactions. When both mirids occur on the same crop, they engage in competition for both plant and animal food sources. Nesidiocoris tenuis is known to occupy higher plant strata than M. pygmaeus (Perdikis et al. 2014), ensuring access to meristematic plant tissue of higher nutritional quality (El-Dessouki et al. 1976; Arnó et al. 2010). Furthermore, whiteflies aggregate on higher plant strata in tomato (Arnó et al. 2006), thus the shared prey becomes more accessible to $N$. tenuis. In addition, $N$. tenuis consumes prey at a higher rate than M. pygmaeus (Perdikis et al. 2009; Mollá et al. 2014) and reproduces faster in most temperature regimes common in tomato greenhouses (Ingegno et al. 2021). The two mirids also engage in asymmetrical IGP favouring N. tenuis (Moreno-Ripoll et al. 2012; Perdikis et al. 2014). Ultimately, after suppressing the population of the pests and its competitor, $N$. tenuis switches to a predominantly plant-feeding diet, causing considerable damage to the tomato crop (Sánchez 2008; Calvo et al. 2009; Moerkens et al. 2020). Growers thus resort to pesticide use against $N$. tenuis, inevitably hampering the populations of $M$. pygmaeus and disrupting their biological control practices. Hence, sustainable countermeasures that reduce damage by $N$. tenuis are urgently needed.

In this study, heterospecific mirid predators were evaluated regarding their competitive interactions with $N$. tenuis. Dicyphus errans (Wolff), Dicyphus bolivari (Lindberg) and Dicyphus cerastii Wagner are naturally occurring species across Europe, spontaneously colonizing tomato plants and offering biocontrol services (Figueiredo et al. 2012; Abbas et al. 2014; Ingegno et al. 2017). First, we studied whether established populations of heterospecific mirids could have a negative effect on the population growth of $N$. tenuis. Second, to understand the mechanisms behind displacement, we assessed the intensity and reciprocity of IGP between these species in the laboratory, and the effect that extraguild prey might have on the outcome of these interactions. In these experiments, the commercially available $M$. pygmaeus was also included. Finally, we tested the preference of $N$. tenuis towards plants previously colonized by conspecifics or heterospecifics, to understand whether the outcome of competitive interactions might influence the host plant choice of $N$. tenuis.

\section{Materials and methods}

\section{Insect rearings}

Macrolophus pygmaeus was reared from individuals provided by Koppert B.V. (Berkel en Rodenrijs, The Netherlands) and originate from populations in southern France. Nesidiocoris tenuis were collected from a commercial tomato grower in the South Holland region (the Netherlands). Dicyphus bolivari, D. cerastii, and D. errans originally came from wild vegetation in Spain, Portugal, and 
Italy, respectively. The Dicyphus predators were identified based on morphological characteristics (Sanchez and Cassis 2018), and were reared for several years in the facilities of Wageningen University \& Research (Messelink et al. 2015). The mirids $N$. tenuis, M. pygmaeus, D. bolivari, and $D$. cerastii were reared on organic flat bean pods (Phaseolus vulgaris L.) in transparent plastic cylinder cages ( $25 \mathrm{~cm}, \mathrm{H} 27 \mathrm{~cm}$; JET 107 PM, Jokey plastic GmbH, Sohland, Germany) with the drilled lid covered with a fine net mesh. The D. errans rearings were maintained on Geranium sp. plants in net cages $(60 \times 60 \times 90 \mathrm{~cm}$; Vermandel, The Netherlands). All rearings were supplied with eggs of Ephestia kuehniella Zeller (Lepidoptera: Pyralidae) mixed with decapsulated cysts of Artemia sp. (Anostraca: Artemiidae) (Entofood, Koppert B.V. Berkel en Rodenrijs, The Netherlands) and kept at $25 \pm 1{ }^{\circ} \mathrm{C}, 70 \pm 10 \% \mathrm{RH}, 16: 8 \mathrm{~L}: \mathrm{D}$.

All mirid species, apart from $N$. tenuis, showed high natural mortality in pilot trials of the IGP laboratory experiments when no supplementary food source was provided, and tomato leaflets were the only available food source. Therefore, to acclimatize these species on tomato, all mirids were separately reared on 5-week-old tomato plants (cv Pink Dream GSPP F1, Sakata Seed Corporation, Japan) in plastic cages $(75 \times 75 \times 115 \mathrm{~cm}$, BugDorm-2400 Insect Rearing Tent, MegaView Science Co., Ltd., Taichung, Taiwan) with supplementary food sources (Ephestia eggs and Artemia cysts) ad libitum, in a greenhouse compartment $\left(22 \pm 1{ }^{\circ} \mathrm{C}\right.$, $60 \pm 10 \%$ RH, 14:10 L:D). First-generation nymphs and adult females from these rearings were used in all laboratory IGP experiments.

\section{Greenhouse experiment with heterospecific mirid establishment prior to N. tenuis release}

In a 4-month greenhouse experiment, the effect of preestablished heterospecific mirids on the population growth of $N$. tenuis was evaluated. Furthermore, the effect $N$. tenuis had on the population growth of the already established heterospecific mirids was studied. Four-week-old and pesticide-free tomato plants cv Brioso (Rijk Zwaan, The Netherlands) grafted upon Maxifort rootstock (de Ruiter, The Netherlands) with 2 stems per plant, were provided by a commercial propagator. Tomato plants were placed individually on Grodan Grotop (C) rockwool slabs in walk-in cages $(1 \times 2 \times 2 \mathrm{~m})$ made of fine insect gauze (mesh size $0.22 \times 0.31 \mathrm{~mm}$ ), and were provided with a standard nutrient solution for tomato plants (Sonneveld and Voogt 2009) through a dripping irrigation system. Plants were vaccinated with a mild isolate of the Pepino mosaic virus (PMV®-01, DCM, Belgium), to offer protection against more aggressive isolates. Standard cultivation practices were followed, including weekly pruning of secondary shoots, leaf picking of the old leaves, and harvesting of ripe fruits. Picked leaves and shoots were left in the cages to allow mirid individuals to recolonize the plants. The experiment was conducted in two identical greenhouse compartments of $98 \mathrm{~m}^{2}$ from June to September 2017. The following seven treatments were tested: (i) $N$. tenuis, (ii) D. errans, (iii) $N$. tenuis \& $D$. errans, (iv) D. cerastii, (v) N. tenuis \& D. cerastii, (vi) D. bolivari and (vii) $N$. tenuis \& D. bolivari. The commercially available mirid predator M. pygmaeus was not included in this experiment due to space limitations. Treatments were assigned following a randomized complete block design, with two blocks in each greenhouse compartment (14 cages in each compartment, for a total of 28 cages and four replicates per treatment). Throughout the experiment, temperature and relative humidity were registered every $5 \mathrm{~min}$ with a climate recorder (Hoogendoorn Growth Management) inside one of the cages. The average measured temperature in the two greenhouse compartments was $21.9^{\circ} \mathrm{C}$ (range $14.8-40{ }^{\circ} \mathrm{C}$ ) and $21.7^{\circ} \mathrm{C}$ (range $13.8-40.6{ }^{\circ} \mathrm{C}$ ) and average relative humidity of $65 \%$ (range $18-90 \%$ ) and $65 \%$ (range 44-81\%).

Mirid predators were released on different timepoints to achieve a stable population of mixed stages. The predator releases started when tomato plants were 5 weeks old (week 1). In weeks 1 and 3, five couples of Dicyphus predators were released. In week 5, ten more Dicyphus couples were introduced, for a total of 20 couples of Dicyphus predators released per cage. In weeks 5 and 7, five couples of $N$. tenuis were introduced to the control (i), as well as the mixed cages (iii, v, and vii), for a total of 10 couples released per cage. All mirid predators introduced were 1-week-old mated adults. During the first 8 weeks of the experiment, the predators in all cages were fed with supplementary food $(0.8 \mathrm{~g}$ of Ephestia eggs during weeks 1-4 and $3 \mathrm{~g}$ of 50:50 mix of Ephestia eggs and Artemia cysts during weeks 5-8). The food was provided weekly and was evenly spread on the plant canopy. Densities of predatory mirids were assessed fortnightly for nine consecutive weeks, starting in week 7 . The whole plant canopy was rigorously examined from the bottom up and all observations were non-destructive. All mirid stages were counted, but as inside the cages it was difficult to identify the species at the nymphal stage, only the number of adults of each species per cage and sample period were included in the statistical analysis. Adult Dicyphus mirids are easily distinguished from those of $N$. tenuis as they are considerably larger, darker in colour, and have characteristic red eyes (Sanchez and Cassis 2018; Ingegno et al. 2021).

\section{Nesidiocoris tenuis nymphs as intraguild prey}

Laboratory trials were conducted to assess the IGP and cannibalism rate of the five adult mirid predators on juvenile individuals of $N$. tenuis. Nymphal stage 2 was selected 
as the age of the intraguild prey for adult mirids, as it is generally accepted that young individuals are more vulnerable to IGP (Lucas 2005; Moreno-Ripoll et al. 2012). Six $N$. tenuis nymphs (N2) were offered to a single 1-week-old adult female of the five different intraguild predators. This density was chosen based on preliminary observations and previously published data with a similar experimental setup (Moreno-Ripoll et al. 2012). The six nymphs and the single adult female mirid were placed on tomato leaflets $\left(55 \pm 10 \mathrm{~cm}^{2}, \mathrm{cv}\right.$ Pink Dream) in ventilated plastic containers $(15 \times 20 \times 10 \mathrm{~cm})$. The petiole of the tomato leaflet was submerged in a 5-ml cylindrical plastic tube filled with water and sealed with Parafilm ${ }^{\circledR}$ to avoid leaflet desiccation over the course of the experiment. A control treatment (no intraguild predator in the experimental arena) was also included to account for natural mortality of nymphs. The experimental arenas were then placed in a climate chamber $\left(25 \pm 1{ }^{\circ} \mathrm{C}, 70 \pm 10 \% \mathrm{RH}, 16: 8 \mathrm{~L}: \mathrm{D}\right)$. Nymphal mortality was assessed visually under a binocular microscope once, after 4 days. Furthermore, to evaluate the effect of extraguild prey on nymphal mortality, we included treatments where E. kuehniella eggs were added ad libitum in the arenas for all intraguild predator-prey combinations. Nymphal mortality of $N$. tenuis as the intraguild prey was thus tested in a total of 12 treatments: (i) Control (no intraguild predator) (ii) $N$. tenuis adult (cannibalism treatment), (iii) M. pygmaeus adult, (iv) D. errans adult, (v) $D$. bolivari adult, vi) $D$. cerastii adult, and all aforementioned treatments in the presence of extraguild prey.

\section{Nesidiocoris tenuis females as intraguild predators}

Laboratory trials were also conducted to assess the IGP and cannibalism rate of $N$. tenuis adult females on juvenile mirids of the other species. Six nymphs (N2) of each of the 5 different species and a single 1-week-old adult female $N$. tenuis were placed in the experimental arenas described above. To account for natural mortality of the five different mirids, control treatments with no intraguild predator were also included. To evaluate the effect of extraguild prey on nymphal mortality, E. kuehniella eggs were added ad libitum in the arenas for all intraguild predator-prey combinations. Thus, the full factorial experiment included three different treatments; intraguild prey with 5 levels (N. tenuis, M. pygmaeus, D. errans, D. bolivari, and $D$. cerastii), intraguild predator with 2 levels ( $N$. tenuis adult female present or absent), and extraguild prey with 2 levels (E. kuehniella eggs present or absent), for a total of 20 treatments. All treatments without extraguild prey were replicated 20 times, while those with extraguild prey were replicated at least 10 times.

\section{Y-tube olfactometer}

Olfactometer tests were conducted to assess whether $N$. tenuis is responding to plant volatiles induced by the mirid species tested in the greenhouse and laboratory trials. Three-week-old tomato plants (cv Pink Dream) were placed in $75 \times 75 \times 115 \mathrm{~cm}$ plastic cages (BugDorm-2400) in a greenhouse compartment $\left(22 \pm 2{ }^{\circ} \mathrm{C}, 70 \pm 10 \% \mathrm{RH}\right)$. Thirty adult mirid predators were randomly selected from the rearing units and released in each cage to feed and oviposit on the plants. The mirids remained on the plants for 7 days, as this time period was assumed to be necessary for the induction of plant defences and the production of herbivore-induced plant volatiles (HIPVs) (Lins et al. 2014). No supplementary food sources were provided in the cages, to ensure plant feeding by the mirids. After 7 days, all adults were removed from the plants via an aspirator. The treated plants along with healthy noninfested plants were then directly transferred in the Y-tube climate room.

Responses of $N$. tenuis females to volatiles were observed in a two-choice Y-shaped Pirex tube $(\varnothing 3.5 \mathrm{~cm})$ formed by an entry arm (20 cm in length) and two side arms $(23 \mathrm{~cm}$ in length, $70^{\circ}$ angle). The Y-tube was positioned vertically as in other studies with Dicyphini (Ingegno et al. 2011; Lins et al. 2014). The two side arms were each connected to a glass container ( $35 \mathrm{~L}$ in volume) harbouring the volatile source. The airflow was provided by an air pump adjusted with a flow meter to $4 \mathrm{~L} / \mathrm{min}$. The glass containers with volatile sources were kept behind black panels, preventing insects from visually detecting the plants. Single 1-weekold female predators were kept without prey and plant tissue in glass tubes (length $120 \mathrm{~mm}, \emptyset 23 \mathrm{~mm}$ ), sealed with a wet cotton ball for $18 \mathrm{~h}$ prior to the assays. They were then introduced at the downwind end of the entry arm and observed until they walked at least $10 \mathrm{~cm}$ up one of the side arms. Females not choosing a side arm within 10 min were considered as having made no choice and were excluded from data analysis. Each female was tested only once. Each plant pair was replicated four times and 20 females were tested on each plant pair, for a total of 80 females tested per treatment. After testing a batch of ten females, the volatile sources were switched between the left and right sides of the arms to minimize positional bias. After testing twenty females, the Y-tube and glass containers were washed with neutral soap and alcohol (70\%) and a new plant pair was introduced. Y-tube bioassays were carried out in a climate room at $22 \pm 1{ }^{\circ} \mathrm{C}, 70 \pm 10 \% \mathrm{RH}$.

The responses of $N$. tenuis females were tested on the following two-choice situations: (i) undamaged plant vs air, (ii) undamaged plant vs $N$. tenuis damaged plant, (iii) undamaged plant vs $M$. pygmaeus damaged plant, (iv) undamaged plant vs D. errans damaged plant, (v) 
undamaged plant vs $D$. bolivari damaged plant and (vi) undamaged plant vs $D$. cerastii damaged plant.

\section{Statistical analyses}

Generalized linear mixed models (GLMM) were fitted for the greenhouse experiment using the glmmTMB function (Brooks et al. 2017). First, the effect of the pre-established Dicyphus predators on the population build-up of $N$. tenuis was tested. A GLMM was fitted with $N$. tenuis as the response variable, and the identity of the Dicyphus predator (including no predator) as the fixed effect. To test the effect $N$. tenuis had on the population build-up of the Dicyphus predator, a GLMM was fitted with Dicyphus adults as the response variable. The fixed effects were the identity of the Dicyphus predator (D. errans, $D$. bolivari, and D. cerastii), the presence/absence of N. tenuis, and their interaction. In both models, block and time were included as random effects, to account for temporal pseudo-replication of measures. Error distributions for both models were tested visually with diagnostic plots (Hartig 2021) and by evaluating the dispersion parameter of the model (Gelman and Hill 2006). Negative binomial distribution was chosen as the best fitting, based on AICc criteria (Burnham and Anderson 2004). The data of the IGP laboratory experiments were analysed through means of generalized linear model (GLM) with binomial error structure. The factorial analysis in the situation where $N$. tenuis nymphs were offered to the 5 different adult predators ( $N$. tenuis as the intraguild prey) included two factors, the extraguild prey (Ephestia eggs; present or absent), and the predator's identity. In the reverse situation, where $N$. tenuis adults were offered nymphs of the five different mirid species ( $N$. tenuis as the intraguild predator), the model included three factors, the absence or presence of the intraguild predator and extraguild prey, as well as the nymph's (prey) species identity with five different levels. As natural mortality during the experiments was different for mirid nymphs acting as intraguild prey and due to significant interaction between intraguild predator and prey, separate models were fitted for each intraguild prey. To account for over- or under-dispersion in the GLMs when detected, the quasibinomial error distribution was used (McCullagh and Nelder 1989). When main effects were found significant, treatment means were compared through Tukey's HSD tests. In the olfactometer experiments, responses of $N$. tenuis females to different pairs of odours were analysed by Pearson's Chi-square Test for Independence. All statistical analyses were performed using the statistical software R 4.0.2 (R Core Team 2021).

\section{Results}

\section{Interspecific competition in the greenhouse}

Nesidiocoris tenuis populations grew large in the absence of its competitors Dicyphus species $\left(\chi^{2}=15.521, d f=3\right.$, $P=0.001$ ), reaching more than 100 adult individuals on average by the end of the experiment (September 2017). All three Dicyphus species reduced the population growth of $N$. tenuis by about $90 \%$ (Fig. 1).

Population growth of the Dicyphus predators was not disrupted by the introduction of $N$. tenuis $\left(\chi^{2}=0.059, d f=1\right.$, $P=0.809)$. Similarly, interaction between Dicyphus species and $N$. tenuis did not have a significant effect on Dicyphus population growth $\left(\chi^{2}=0.596, d f=2, P=0.742\right)$. However, differences were found in the population build-up of the Dicyphus predators in our study $\left(\chi^{2}=38.518, d f=2\right.$, $P<0.001$ ), with $D$. cerastii maintaining high overall populations compared to those of D. bolivari and D. errans (Fig. 2).

\section{Nesidiocoris tenuis nymphs as intraguild prey}

Mortality of $N$. tenuis nymphs was influenced by the presence of the intraguild predator $\left(\chi^{2}=51.178, d f=5\right.$, $P \leq 0.001$ ), with all Dicyphus predators and N. tenuis (cannibalism) causing significantly more mortality than $M$. pygmaeus and the control treatment (no intraguild predator) (Fig. 3). The effect of extraguild prey

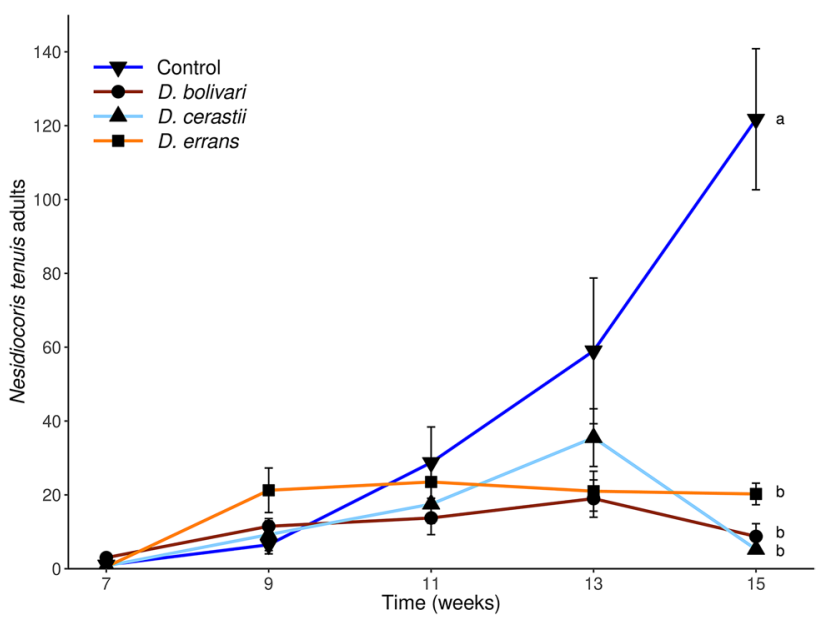

Fig. 1 Population dynamics of Nesidiocoris tenuis in tomato with or without a competitor Dicyphus predator present. Dicyphus mirids were released in weeks 1 ( 5 couples), 3 (5 couples), and 5 (10 couples) and $N$. tenuis in weeks 5 (5 couples) and 7 (5 couples). Supplementary food was offered in the cages weekly up to week 8 . The average number $( \pm \mathrm{SE})$ of adult $N$. tenuis is shown through time. Different letters indicate significant differences in $N$. tenuis population among treatments through time (GLMM, Tukey's HSD, $P<0.05$ ) 


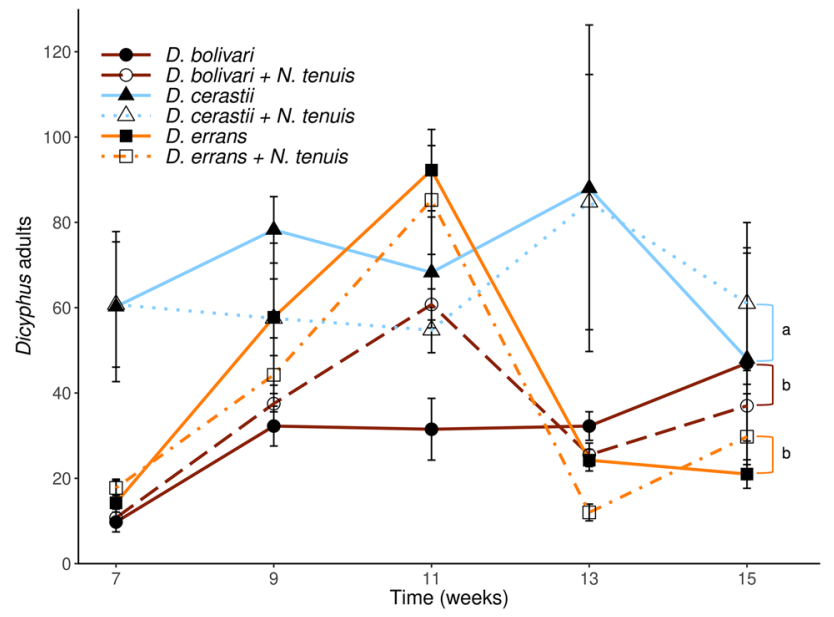

Fig. 2 Population dynamics of adult Dicyphus predators on tomato plants where the competitor $N$. tenuis was introduced or not. Dicyphus mirids were released in weeks 1 (5 couples), 3 (5 couples), and 5 (10 couples) and $N$. tenuis in weeks 5 (5 couples) and 7 (5 couples). Supplementary food was offered in the cages weekly up to week 8 . The average number $( \pm \mathrm{SE})$ of the Dicyphus species is shown through time. As $N$. tenuis did not affect the population dynamics of Dicyphus predators, different letters indicate significant differences in population growth of Dicyphus predators through time (GLMM, Tukey's HSD, $P<0.05)$

(Ephestia eggs) was also found significant $\left(\chi^{2}=43.775\right.$, $\mathrm{df}=1, P \leq 0.001$ ). Almost no $N$. tenuis nymphal mortality was recorded when Ephestia eggs were present in the experimental arenas. The effect of the Ephestia eggs was not influenced by the intraguild predator's identity $\left(\chi^{2}=2.144, d f=1, P=0.6226\right)$.

\section{Nesidiocoris tenuis females as intraguild predators}

A three-factor analysis with extraguild prey, intraguild prey, and intraguild predator indicated significant interaction between the latter two (Table 1). Furthermore, natural mortality of mirids tested differed significantly between species (Fig. 4), thus no comparisons between the different intraguild preys were made. Instead, the mortality for each intraguild prey species was analysed separately. For all intraguild prey tested, natural mortality decreased significantly in the presence of extraguild prey (Ephestia eggs), apart from $N$. tenuis which exhibited low natural mortality in both situations (Fig. 4). The presence of the intraguild predator (N. tenuis) had a significant effect on prey mortality in all predator-prey combinations in the absence of extraguild prey, apart from $D$. bolivari. In the presence of extraguild prey, the intraguild predator did not affect the mortality of intraguild prey.

\section{Nesidiocoris tenuis responses to previously damaged plants}

Female $N$. tenuis showed a strong preference towards undamaged tomato plants, when the alternative was just clean air $\left(\chi^{2}=30.564, P<0.001\right)$. No preference was found between undamaged tomato plants and those previously exposed to D. errans $\left(\chi^{2}=2.469, P=0.116\right), D$. bolivari $\left(\chi^{2}=1.333\right.$, $P=0.248)$, and conspecifics $\left(\chi^{2}=0.018, P=0.893\right)$. However, preference was found to be significant towards plants previously exposed to $M$. pygmaeus $\left(\chi^{2}=4.412, P=0.036\right)$ and $D$. cerastii $\left(\chi^{2}=4.923, P=0.027\right)$. The number of nonresponding females was moderate, ranging between around $30 \%$ and $40 \%$, regardless of the treatment pair tested (Fig. 5).
Fig. 3 Average mortality $( \pm \mathrm{SE})$ of $N$. tenuis nymphs (N2-N3) in the presence of different intraguild predators, and presence or not of extraguild prey (Ephestia eggs) in the experimental arenas after 4 days. A treatment with no intraguild predator is included to evaluate the natural mortality of $N$. tenuis nymphs. Different letters indicate significant differences in mortality of $N$. tenuis nymphs in the absence or presence of extraguild prey (GLM, Tukey's HSD, $P<0.05)$

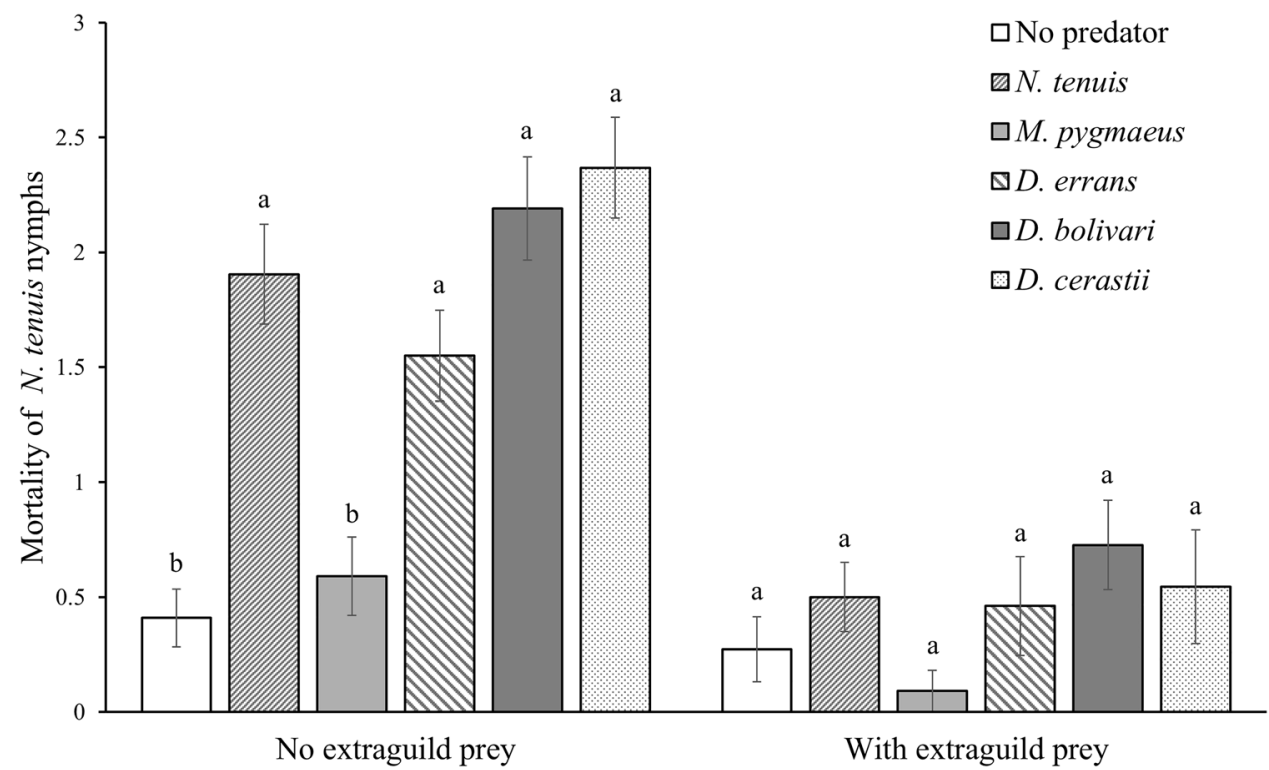


Table 1 Results of logistic regression on the effect of extraguild prey (Ephestia eggs presence or absence), intraguild predator (N. tenuis female present or absent), and intraguild prey (N. tenuis, $M$. pygmaeus, $D$. errans, $D$. bolivari, or $D$. cerastii nymphs) on the mortality of intraguild prey

\begin{tabular}{llrrr}
\hline Data set & Source of variation & Df & Wald $\chi^{2}$ & $P$ \\
\hline $\begin{array}{l}\text { Complete factorial } \\
\text { analysis }\end{array}$ & Extraguild prey & 1 & 105.904 & $<\mathbf{0 . 0 0 1}$ \\
& Intraguild predator & 1 & 56.053 & $<\mathbf{0 . 0 0 1}$ \\
& Intraguild prey & 4 & 31.112 & $<\mathbf{0 . 0 0 1}$ \\
& Extraguild prey $\times$ Intraguild predator & 1 & 0.384 & 0.421 \\
& Extraguild prey $\times$ Intraguild prey & 4 & 4.914 & 0.081 \\
& Intraguild predator $\times$ Intraguild prey & 4 & 6.933 & $\mathbf{0 . 0 2 0}$ \\
& Extraguild prey $\times$ Intraguild preda- & 4 & 2.047 & 0.484 \\
N. tenuis & tor $\times$ Intraguild prey & & & \\
& Extraguild prey & 1 & 9.667 & $<\mathbf{0 . 0 0 1}$ \\
& Intraguild predator & 1 & 18.823 & $<\mathbf{0 . 0 0 1}$ \\
M. pygmaeus & Extraguild prey $\times$ Intraguild predator & 1 & 1.198 & 0.152 \\
& Extraguild prey & 1 & 38.556 & $<\mathbf{0 . 0 0 1}$ \\
& Intraguild predator & 1 & 14.295 & $<\mathbf{0 . 0 0 1}$ \\
& Extraguild prey $\times$ Intraguild predator & 1 & 0.270 & 0.449 \\
D. errans & Extraguild prey & 1 & 28.336 & $<\mathbf{0 . 0 0 1}$ \\
& Intraguild predator & 1 & 13.744 & $<\mathbf{0 . 0 0 1}$ \\
& Extraguild prey $\times$ Intraguild predator & 1 & 0.009 & 0.905 \\
D. bolivari & Extraguild prey & 1 & 11.004 & $<\mathbf{0 . 0 0 1}$ \\
& Intraguild predator & 1 & 3.135 & $\mathbf{0 . 0 1 3}$ \\
& Extraguild prey $\times$ Intraguild predator & 1 & 0.458 & 0.341 \\
& Extraguild prey & 1 & 21.921 & $<\mathbf{0 . 0 0 1}$ \\
& Intraguild predator & 1 & 12.839 & $<\mathbf{0 . 0 0 1}$ \\
& Extraguild prey $\times$ Intraguild predator & 1 & 0.369 & 0.489 \\
\hline & & & &
\end{tabular}

Bold $P$ values repsesent significance $<0.05$
Fig. 4 Average mortality $( \pm S E)$ of mirid nymphs (N2-N3) in the presence or absence of $N$. tenuis females acting as intraguild predators, and presence or not of extraguild prey (Ephestia eggs) in the experimental arenas after 4 days (IP $=$ intraguild predator, $\mathrm{EP}=$ extraguild prey). Control bars show the natural mortality of mirid nymphs in the absence of both IP and EP. Different letters indicate significant differences in nymphal mortality among treatments per mirid species acting as intraguild prey (GLM, Tukey's HSD, $P<0.05)$

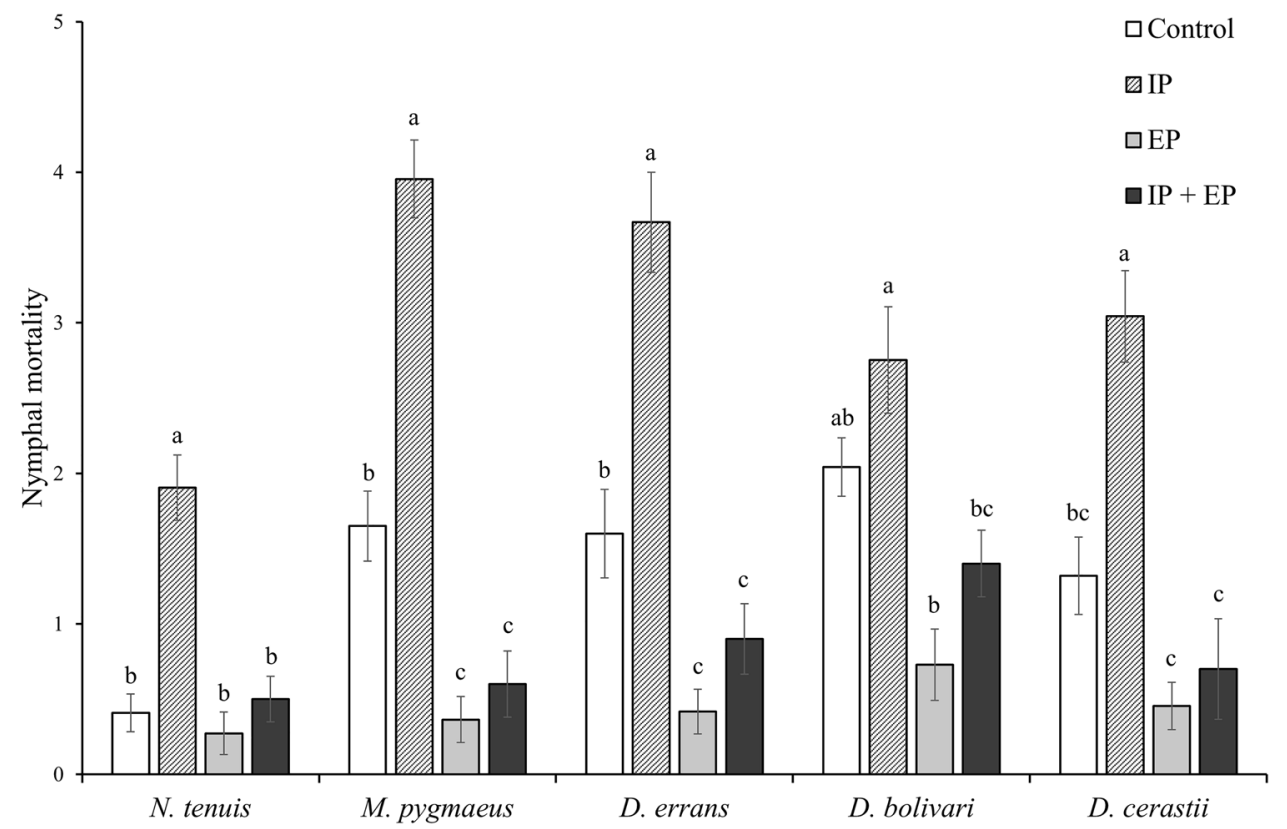

\section{Discussion}

The greenhouse experiment simulated the invasion of $N$. tenuis in tomato plants where heterospecific mirids were already established. The prior establishment of Dicyphus predators had a strong negative effect on the population growth of $N$. tenuis, lowering its population growth by more than $90 \%$. These results suggest that Dicyphus predators can be used effectively to slow down the population 

females to plants previously damaged by mirids or no odour source (clean air) in a Y-tube olfactometer. Numbers in bars represent individuals that moved towards the odour source indicated. $P$ values based on Pearson's Chi-square test for independence. $* P \leq 0.05$, $* * *$ $P<0.001$. Non-responding individuals are shown in column no choice
Fig. 5 Responses of $N$. tenuis

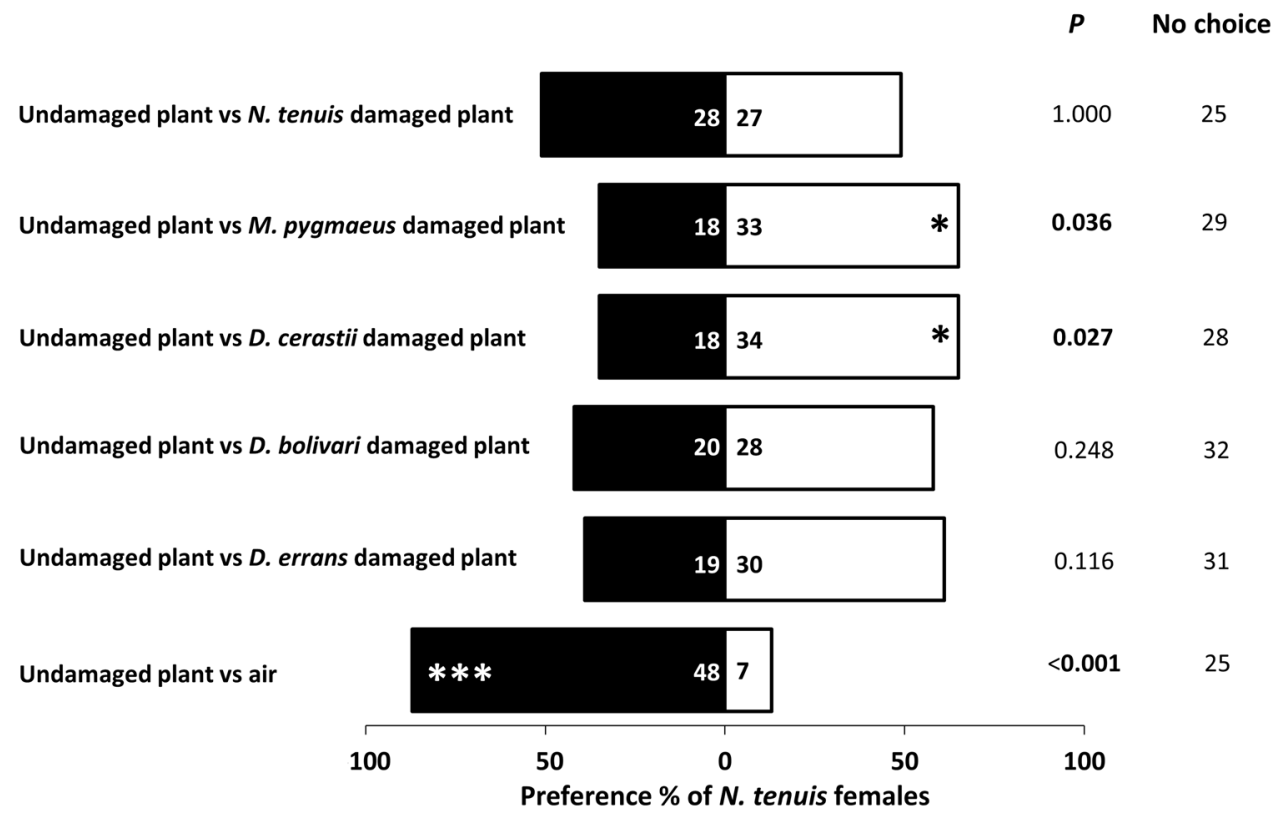

growth of $N$. tenuis under the studied ratios and environmental conditions. Salas Gervassio et al. (2017) also found that the presence of $D$. bolivari in tomato plants limited the population growth of $N$. tenuis at $25^{\circ} \mathrm{C}$ when released at equal densities. However, the population of $D$. bolivari in their study remained low in the presence of $N$. tenuis. Introducing $N$. tenuis did not disturb the population growth of the established three Dicyphus species in our study. This shows that under the studied ratios, $N$. tenuis cannot competitive displace already established Dicyphus heterospecifics. However, when released simultaneously and at same initial densities, $N$. tenuis developed much larger populations than D. bolivari when E. kuehniella eggs were present as extraguild prey (Salas Gervassio et al. 2017). The overall greater reproduction capacity of $N$. tenuis compared to D. bolivari (Abbas et al. 2014), M. pygmaeus (Mollá et al. 2014), and D. errans (Perdikis and Arvaniti 2016), in conjunction with its shorter developmental cycle at moderate and high temperatures (Ingegno et al. 2021), gives $N$. tenuis a vital edge over its competitors. We therefore expect that only an already established population of heterospecific mirids can prevent $N$. tenuis outbreaks, as shown in our study.

The populations of the Dicyphus species fluctuated throughout the experimental timeframe (Fig. 2). Dicyphus bolivari did not reach high populations, suggesting that for this species tomato is not a preferred host plant. The low survival rate $D$. bolivari nymphs exhibited in our laboratory experiments on tomato leaflets corroborates this. Dicyphus cerastii maintained high populations throughout the greenhouse experiment. Contrastingly, D. errans populations decreased late in the experimental timeframe. Intraspecific competition, and specifically high cannibalism rate (Arvaniti et al. 2019) may explain the reduction in population for this species when supplementary food sources were no longer offered to the predators. These findings suggest strong dependence of $D$. errans and $D$. bolivari on animal prey when developing on tomato plants.

The emerging $N$. tenuis progeny in the greenhouse experiment were vulnerable to IGP from the high population of heterospecific predators already present on plants. The results of the IGP experiments showed that Dicyphus adults may act as intraguild predators against young nymphal stages of $N$. tenuis. While $D$. bolivari $(=D$. maroccanus) and D. cerastii have previously been reported to predate on N. tenuis nymphs (Salas Gervassio et al. 2017; Abraços Duarte et al. 2021), here we show that the same applies to D. errans. However, M. pygmaeus females did not predate on $N$. tenuis, in agreement with previous studies (Moreno-Ripoll et al. 2012; Perdikis et al. 2014). This finding may be due to the overall lower aggressiveness of this species compared to the Dicyphus predators. In a series of observational experiments, $M$. pygmaeus (erroneously identified as M. caliginosus (Martinez-Cascales et al. 2006)) was found to be more energetically conservative in its foraging, leading to low encounter and predation rates on whiteflies compared to a Dicyphus predator (Montserrat et al. 2004). These behavioural characteristics may partially explain why M. pygmaeus is outcompeted in tomato greenhouses by $N$. tenuis through exploitative competition for the shared prey in combination with IGP.

In our laboratory study, $N$. tenuis females engaged in IGP on nymphs of D. errans, D. cerastii, and M. pygmaeus. Remarkably, D. bolivari did not suffer significant IGP. However, this species exhibited high natural mortality during the experiments, which might have enabled the $N$. tenuis to 
feed on already dead individuals in the experimental arenas. Indeed, zoophytophagous mirids are known to feed on already dead conspecifics and heterospecifics (Lucas and Alomar 2001; Moreno-Ripoll et al. 2014; Wheeler and Krimmel 2015). Furthermore, we found that $N$. tenuis exhibited significant cannibalism on conspecific nymphs, in agreement with previous studies (Fernandez et al. 2020). Cannibalism is a common phenomenon in the mirid family (Wheeler 2001) and other carnivorous and herbivorous insects (Fox 1975). However, because cannibalism and IGP rates found in this study were similar, it seems that $N$. tenuis does not discriminate between conspecific and heterospecific nymphs when in need of animal prey. Likewise, no differences between IGP and cannibalism rates were found in a study involving two omnivorous anthocorid predators (Tommasini et al. 2002).

The presence of extraguild prey (E. kuehniella eggs) diminished the occurrence of IGP in all predator-prey combinations as well as cannibalism events (Lucas and Rosenheim 2011; Perdikis et al. 2014). Adult intraguild predators had ample access to a nutritionally optimal and defenceless food source, reducing the need of predating on mirid nymphs. Mirid nymphs killed by freezing are known to be of high nutritional value to mirid predators (Lucas and Alomar 2001), yet while being alive they may be difficult to subdue. Therefore, the agile nature of mirid nymphs may render them less vulnerable to IGP or cannibalism. This hypothesis is further supported by the low consumption rate of adults in our experimental arenas in the absence of extraguild prey ( $\sim 2$ predated mirid nymphs in 4 days), while when predating on sessile aphids, adult predators consume more than 20 nymphs (similar size with mirid nymphs) in $24 \mathrm{~h}$ (Messelink et al. 2015; Abraços-Duarte et al. 2021). Yet, despite the relatively low predation rates of adult Dicyphus predators on $N$. tenuis nymphs and the absence of IGP in the presence of extraguild prey, we still observed a very strong effect of the pre-established population of Dicyphus predators on the population growth of $N$. tenuis in the greenhouse trial. A possible explanation could be that the low intraguild predation rates were compensated by high intraguild predator densities in the greenhouse trial. Furthermore, the availability of extraguild prey on plants was more limited than in the laboratory trial because of consumption. Finally, on plants, maybe also other unknown mechanisms might have played a role in the observed effects on $N$. tenuis population growth.

In the olfactometer bioassays, $N$. tenuis females did not show any preference between plants that were undamaged and those previously colonized by conspecifics. This finding was contrary to our expectations and recent literature. Lins et al. (2014) reported that $N$. tenuis females were attracted to tomato plants damaged by conspecifics after 10 days of plant feeding, but not after 4 days. Furthermore, in their recent work on eggplant and sesame plants, Rim et al.
(2018) demonstrated that the attractiveness of $N$. tenuis to conspecifically damaged plants is gender dependent. Specifically, females were only attracted to mated female damaged plants, suggesting that plant responses to oviposition may be responsible for the attractiveness. Similar findings have been reported for M. caliginosus (Moayeri et al. 2007). It has been suggested that repeated feeding on the same sites by $N$. tenuis causes biochemical changes that could result in attractance through volatile cues (Arnó et al. 2010). However, it was later shown that no nutritional benefit was obtained by feeding on the same site by $N$. tenuis, while nymphal development was inferior compared to undamaged plant tissue (Sanchez et al. 2016). Nevertheless, aggregation of mirid nymphs around necrotic rings caused by previous feeding punctures is common (personal observations). This may be explained by the increased phytophagy exhibited by nymphal stages compared to adults (Chinchilla-Ramírez et al. 2021), leading to higher plant damage potential (Calvo et al. 2009; Perdikis et al. 2009). Thus, attractiveness to previously damaged tissue may be more important for mirid nymphs and mediated by short-distance cues. Sibling cannibalism between similarly sized $N$. tenuis nymphs is known to occur (Fernandez et al. 2020), yet the benefit of feeding on already macerated and easily accessible plant tissue may outweigh the risk of cannibalism. Adult females of $N$. tenuis were not attracted towards previously infested plants by conspecifics in our study, suggesting that intraspecific competition may not be strong. Indeed, cannibalism in heteropteran omnivorous predators is known to be less important than in strict carnivores (Fernandez et al. 2020).

HIPVs emitted by plants exposed to herbivory by mirids are species dependent. The tomato leafminer Tuta absoluta (Meyrick) (Lepidoptera: Gelechiidae) avoided plants previously exposed to plant feeding by $N$. tenuis, but preferred those previously exposed to $M$. pygmaeus and $D$. bolivari (Pérez-Hedo et al. 2015). It was later shown that HIPVs emitted and phytohormone pathways activated by these mirid predators were different, most likely due to their different feeding styles (Pérez-Hedo et al. 2015, 2017). However, little is known about how these species-specific plant responses affect plant preference by heterospecific mirids. The results of our study demonstrate for the first time that $N$. tenuis is attracted to plants previously colonized by M. pygmaeus. A similar attractive trend was observed on plants previously colonized by the Dicyphus predators, yet this preference was only significant towards $D$. cerastii damaged plants. This finding may be due to higher plantfeeding activity of $D$. cerastii on tomato, as this species was also found to build the highest populations in the tomato greenhouse trial. Overall, these findings suggest that plant responses from Dicyphus spp. herbivory are similar to those of M. pygmaeus, as it has been reported previously for $D$. bolivari (Pérez-Hedo et al. 2015). From an ecological 
perspective, our results suggest that IGP by heterospecifics is not perceived as a risk by foraging $N$. tenuis females. Furthermore, when encountering heterospecifics, $N$. tenuis establishes successfully in its preferred plant parts (Perdikis et al. 2014), and may ultimately outcompete heterospecific mirids in tomato crops (Salas Gervassio et al. 2017; Abraços Duarte et al. 2021). Therefore, previously colonized plants may indicate an opportunity of a suitable host plant with availability of prey rather than a risk, explaining the attractiveness for $N$. tenuis.

Mirids act as top predators in the food web of tomato greenhouses. When different species co-occur, they compete for the shared animal prey and plant-feeding sites. Through increased aggressiveness and higher reproductive potential, $N$. tenuis commonly outcompetes already established heterospecifics through the growing season (Salas Gervassio et al. 2017; Abraços Duarte et al. 2021). The results of this study demonstrate that a high previously established population of Dicyphus mirid predators can effectively reduce the population growth of $N$. tenuis through interspecific competition in the absence of extraguild prey. We further showed that IGP between these species does occur and may influence the community structure, yet its intensity is low and its significance in agroecosystems should not be overestimated. We suggest that future research should now focus on the effects of Dicyphus predators on pest suppression alone or in combination with the commercially available M. pygmaeus. Studies on the interactions of multiple mirids will deepen our understanding on the role of omnivores in agroecosystems and may lead to effective and sustainable strategies against $N$. tenuis. Furthermore, recent research on the use of fungal endophytes to reduce plant damage and enhance pest control by omnivorous mirids (Garantonakis et al. 2018; Eschweiler et al. 2019) might create new opportunities in developing resilient pest control strategies, while reducing plant damage by this controversial group of predators.

\section{Authors' contributions}

$\mathrm{AM}$ and GM conceived and designed the trials and wrote the manuscript. AM and AL conducted the experiments. AM, GM, and EHP analysed the data. All authors read and approved the manuscript.

Funding The greenhouse trial was funded by the Dutch top sector Horticulture and Starting Materials. AM was the recipient of a M.Sc. scholarship by Bodossaki Foundation (Greece).

Availability of data and materials (data transparency) The datasets supporting this article can be obtained from Mendeley Data: https://doi. org/10.17632/3r9bhmhz6d.1
Code availability (software application or custom code) Not applicable.

\section{Declarations}

Conflict of interest The authors declare no conflict of interest.

Open Access This article is licensed under a Creative Commons Attribution 4.0 International License, which permits use, sharing, adaptation, distribution and reproduction in any medium or format, as long as you give appropriate credit to the original author(s) and the source, provide a link to the Creative Commons licence, and indicate if changes were made. The images or other third party material in this article are included in the article's Creative Commons licence, unless indicated otherwise in a credit line to the material. If material is not included in the article's Creative Commons licence and your intended use is not permitted by statutory regulation or exceeds the permitted use, you will need to obtain permission directly from the copyright holder. To view a copy of this licence, visit http://creativecommons.org/licenses/by/4.0/.

\section{References}

Abbas S, Pérez-Hedo M, Colazza S, Urbaneja A (2014) The predatory mirid Dicyphus maroccanus as a new potential biological control agent in tomato crops. Biocontrol 59:565-574. https:// doi.org/10.1007/s10526-014-9587-6

Abraços Duarte G, Caldas F, Pechirra A et al (2021) Intraguild predation and cannibalism among Dicyphini: Dicyphus cerastii vs. two commercialized species. Entomol Exp Appl 169:90-96. https://doi.org/10.1111/eea.12943

Abraços-Duarte G, Ramos S, Valente F et al (2021) Functional response and predation rate of Dicyphus cerastii Wagner (Hemiptera: Miridae). Insects 12:1-16. https://doi.org/10.3390/ insects 12060530

Arnó J, Albajes R, Gabarra R (2006) Within-plant distribution and sampling of single and mixed infestations of Bemisia tabaci and Trialeurodes vaporariorum (Homoptera: Aleyrodidae) in winter tomato crops. J Econ Entomol 99:331-340. https://doi. org/10.1093/jee/99.2.331

Arnó J, Castañé C, Riudavets J, Gabarra R (2010) Risk of damage to tomato crops by the generalist zoophytophagous predator Nesidiocoris tenuis (Reuter) (Hemiptera: Miridae). Bull Entomol Res 100:105-115. https://doi.org/10.1017/S0007485309006841

Arvaniti K, Fantinou A, Perdikis D (2019) Cannibalism among same-aged nymphs of the omnivorous predator Dicyphus errans (Hemiptera: Miridae) is affected by food availability and nymphal density. Eur J Entomol 116:302-308. https://doi.org/10. 14411/eje.2019.033

Brooks ME, Kristensen K, van Benthem KJ et al (2017) glmmTMB balances speed and flexibility among packages for zero-inflated generalized linear mixed modeling. R J 9:378-400. https://doi. org/10.32614/rj-2017-066

Burnham KP, Anderson DR (2004) Multimodel inference: Understanding AIC and BIC in model selection. Sociol Methods Res 33:261-304. https://doi.org/10.1177/0049124104268644

Calvo J, Bolckmans K, Stansly PA, Urbaneja A (2009) Predation by Nesidiocoris tenuis on Bemisia tabaci and injury to tomato. Biocontrol 54:237-246. https://doi.org/10.1007/s10526-008-9164-y

Calvo FJ, Lorente MJ, Stansly PA, Belda JE (2012) Preplant release of Nesidiocoris tenuis and supplementary tactics for control of Tuta absoluta and Bemisa tabaci in greenhouse tomato. 
Entomol Exp Appl 143:111-119. https://doi.org/10.1111/j. 1570-7458.2012.01238.x

Castañé C, Arnó J, Gabarra R, Alomar O (2011) Plant damage to vegetable crops by zoophytophagous mirid predators. Biol Control 59:22-29. https://doi.org/10.1016/j.biocontrol.2011.03.007

Chinchilla-Ramírez M, Garzo E, Fereres A et al (2021) Plant feeding by Nesidiocoris tenuis: Quantifying its behavioral and mechanical components. Biol Control 152:104402. https://doi.org/10. 1016/j.biocontrol.2020.104402

Coll M, Guershon M (2002) Omnivory in terrestrial arthropods: mixing plant and prey diets. Annu Rev Entomol 47:267-297. https://doi.org/10.1146/annurev.ento.47.091201.145209

Cuny MAC, Bourne ME, Dicke M, Poelman EH (2021) The enemy of my enemy is not always my friend: Negative effects of carnivorous arthropods on plants. Funct Ecol 00:1-11. https://doi. org/10.1111/1365-2435.13884

El-Dessouki SA, El-Kifl AH, Helal A (1976) Life cycle, host plants and symptoms of damage of the tomato bug, Nesidiocoris tenuis Reut. (Hemiptera: Miridae), in Egypt. J Plant Dis Prot 83:201202. https://www.jstor.org/stable/43214057

Eschweiler J, van Holstein-Saj R, Kruidhof HM et al (2019) Tomato Inoculation with a non-pathogenic strain of Fusarium oxysporum enhances pest control by changing the feeding preference of an omnivorous predator. Front Ecol Evol 7:1-9. https://doi.org/10. 3389/fevo.2019.00213

Fernandez FJ, Gamez M, Garay J, Cabello T (2020) Do development and diet determine the degree of cannibalism in insects? To eat or not to eat conspecifics. Insects 11:242. https://doi.org/10.3390/ insects 11040242

Figueiredo E, Prieto R, Mexia A et al (2012) Mirid bugs as biological control agents in protected tomato crops in the oeste region. Acta Hortic 927:253-259. https://doi.org/10.17660/ActaHortic. 2012.927.28

Fox LR (1975) Cannibalism in natural populations. Annu Rev Ecol Syst 6:87-106. https://doi.org/10.1146/annurev.es.06.110175. 000511

Garantonakis N, Pappas ML, Varikou K et al (2018) Tomato inoculation with the endophytic strain Fusarium solani K results in reduced feeding damage by the zoophytophagous predator Nesidiocoris tenuis. Front Ecol Evol 6:126. https://doi.org/10.3389/fevo. 2018.00126

Gelman A, Hill J (2006) Data analysis using regression and multilevel/ hierarchical models. Cambridge University Press, UK

Hagler JR, Naranjo SE (2005) Use of a gut content ELISA to detect whitefly predator feeding activity after field exposure to different insecticide treatments. Biocontrol Sci Technol 15:321-339. https://doi.org/10.1080/09583150500086474

Hartig F (2021) Residual diagnostics for hierarchical (multi-level/ mixed) regression models. $\mathrm{R}$ package version 0.4 .4 . http://flori anhartig.github.io/DHARMa/

Ingegno BL, Pansa MG, Tavella L (2011) Plant preference in the zoophytophagous generalist predator Macrolophus pygmaeus (Heteroptera: Miridae). Biol Control 58:174-181. https://doi.org/10. 1016/j.biocontrol.2011.06.003

Ingegno BL, Messelink GJ, Leman A et al (2021) Development and thermal activity thresholds of European mirid predatory bugs. Biol Control 152:104423. https://doi.org/10.1016/j.biocontrol. 2020.104423

Ingegno BL, Bodino N, Leman A, et al (2017) Predatory efficacy of Dicyphus errans on different prey. Acta Hortic 1164:425-430. https://doi.org/10.17660/ActaHortic.2017.1164.55

Kessler A, Baldwin IT (2004) Herbivore-induced plant vaccination. Part I. The orchestration of plant defenses in nature and their fitness consequences in the wild tobacco Nicotiana attenuata. Plant J 38:639-649. https://doi.org/10.1111/j.1365-313X.2004.02076.x
Lins JC, van Loon JJA, Bueno VHP et al (2014) Response of the zoophytophagous predators Macrolophus pygmaeus and Nesidiocoris tenuis to volatiles of uninfested plants and to plants infested by prey or conspecifics. Biocontrol 59:707-718. https://doi.org/10. 1007/s10526-014-9602-y

Lucas É, Alomar O (2001) Macrolophus caliginosus (Wagner) as an Intraguild Prey for the Zoophytophagous Dicyphus tamaninii Wagner (Heteroptera: Miridae). Biol Control 20:147-152. https:// doi.org/10.1006/bcon.2000.0890

Lucas É, Rosenheim JA (2011) Influence of extraguild prey density on intraguild predation by heteropteran predators: a review of the evidence and a case study. Biol Control 59:61-67. https://doi.org/ 10.1016/j.biocontrol.2011.05.010

Lucas E (2005) Intraguild predation among aphidophagous predators. Eur J Entomol 102:351-364. https://doi.org/10.14411/eje.2005. 052

Martinez-Cascales JI, Cenis JL, Cassis G, Sanchez JA (2006) Species identity of Macrolophus melanotoma (Costa 1853) and Macrolophus pygmaeus (Rambur 1839) (Insecta: Heteroptera: Miridae) based on morphological and molecular data and bionomic implications. Insect Syst Evol 37:385-404. https://doi.org/10.1163/ 187631206788831470

McCullagh P, Nelder JA (1989) Generalized linear models, 2nd edn. In: Applied statistics. Springer, Berlin, p 532

Messelink GJ, Bloemhard CMJ, Hoogerbrugge H et al (2015) Evaluation of mirid predatory bugs and release strategy for aphid control in sweet pepper. J Appl Entomol 139:333-341. https://doi.org/10. 1111 /jen.12170

Moayeri HRS, Ashouri A, Brødsgaard HF, Enkegaard A (2007) Males of the predatory mirid bug Macrolophus caliginosus exploit plant volatiles induced by conspecifics as a sexual synomone. Entomol Exp Appl 123:49-55. https://doi.org/10.1111/j.1570-7458.2007. 00523.x

Moerkens R, Pekas A, Bellinkx S et al (2020) Nesidiocoris tenuis as a pest in Northwest Europe: Intervention threshold and influence of Pepino mosaic virus. J Appl Entomol 144:566-577. https://doi. org/10.1111/jen.12789

Mollá O, Biondi A, Alonso-Valiente M, Urbaneja A (2014) A comparative life history study of two mirid bugs preying on Tuta absoluta and Ephestia kuehniella eggs on tomato crops: Implications for biological control. Biocontrol 59:175-183. https://doi.org/10. 1007/s10526-013-9553-8

Montserrat M, Albajes R, Castañé C (2004) Behavioral responses of three plant-inhabiting predators to different prey densities. Biol Control 30:256-264. https://doi.org/10.1016/J.BIOCONTROL. 2004.01.006

Moreno-Ripoll R, Gabarra R, Symondson WOC et al (2014) Do the interactions among natural enemies compromise the biological control of the whitefly Bemisia tabaci? J Pest Sci 87(2004):133141. https://doi.org/10.1007/s10340-013-0522-x

Moreno-Ripoll R, Agustí N, Berruezo R, Gabarra R (2012) Conspecific and heterospecific interactions between two omnivorous predators on tomato. Biol Control 62:189-196. https://doi.org/10.1016/j. biocontrol.2012.04.005

Perdikis D, Arvaniti K (2016) Nymphal development on plant vs. leaf with and without prey for two omnivorous predators: Nesidiocoris tenuis (Reuter, 1895) (Hemiptera: Miridae) and Dicyphus errans (Wolff, 1804) (Hemiptera: Miridae). Entomol Gen 35:297-306. https://doi.org/10.1127/entomologia/2016/0219

Perdikis D, Fantinou A, Garantonakis N et al (2009) Studies on the damage potential of the predator Nesidiocoris tenuis on tomato plants. Bull Insectology 62:41-46

Perdikis D, Lucas E, Garantonakis N et al (2009) Intraguild predation between Macrolophus pygmaeus and Nesidiocoris tenuis. IOBC/ WPRS Bull 49:301-304 
Perdikis D, Lucas E, Garantonakis N et al (2014) Intraguild predation and sublethal interactions between two zoophytophagous mirids, Macrolophus pygmaeus and Nesidiocoris tenuis. Biol Control 70:35-41. https://doi.org/10.1016/j.biocontrol.2013.12.003

Pérez-Hedo M, Bouagga S, Jaques JA et al (2015) Tomato plant responses to feeding behavior of three zoophytophagous predators (Hemiptera: Miridae). Biol Control 86:46-51. https://doi.org/ 10.1016/j.biocontrol.2015.04.006

Pérez-Hedo M, Urbaneja-Bernat P, Jaques JA et al (2015) Defensive plant responses induced by Nesidiocoris tenuis (Hemiptera: Miridae) on tomato plants. J Pest Sci 88(2004):543-554. https://doi. org/10.1007/s10340-014-0640-0

Pérez-Hedo M, Rambla JL, Granell A, Urbaneja A (2017) Biological activity and specificity of Miridae-induced plant volatiles. Biocontrol 63:1-11. https://doi.org/10.1007/s10526-017-9854-4

Pérez-Hedo M, Riahi C, Urbaneja A (2021) Use of zoophytophagous mirid bugs in horticultural crops: Current challenges and future perspectives. Pest Manag Sci 77:33-42. https://doi.org/10.1002/ ps. 6043

Pimm SL, Lawton JH (1978) On feeding on more than one trophic level. Nature 275:542-544. https://doi.org/10.1038/275542a0

Put K, Bollens T, Wäckers FL, Pekas A (2012) Type and spatial distribution of food supplements impact population development and dispersal of the omnivore predator Macrolophus pygmaeus (Rambur) (Hemiptera: Miridae). Biol Control 63:172-180. https://doi. org/10.1016/j.biocontrol.2012.06.011

R Core Team (2021) R: A Language and Environment for Statistical Computing. R Foundation for Statistical Computing, Vienna, Austria. https://www.r-project.org/

Rim H, Uefune M, Ozawa R, Takabayashi J (2018) An omnivorous arthropod, Nesidiocoris tenuis, induces gender-specific plant volatiles to which conspecific males and females respond differently. Arthropod Plant Interact 12:495-503. https://doi.org/10.1007/ s11829-018-9612-2

Rosenheim JA, Kaya HK, Ehler LE et al (1995) Intraguild predation among biological-control agents: Theory and evidence. Biol Control 5:303-335. https://doi.org/10.1006/bcon.1995.1038

Salas Gervassio NG, Pérez-Hedo M, Luna MG, Urbaneja A (2017) Intraguild predation and competitive displacement between Nesidiocoris tenuis and Dicyphus maroccanus, two biological control agents in tomato pests. Insect Sci 24:809-817. https://doi.org/10. $1111 / 1744-7917.12361$

Sánchez JA (2008) Zoophytophagy in the plantbug Nesidiocoris tenuis. Agric for Entomol 10:75-80. https://doi.org/10.1111/j.1461-9563. 2007.00357.x
Sánchez JA (2009) Density thresholds for Nesidiocoris tenuis (Heteroptera: Miridae) in tomato crops. Biol Control 51:493-498. https:// doi.org/10.1016/j.biocontrol.2009.09.006

Sánchez JA, Lacasa A (2008) Impact of the Zoophytophagous Plant Bug Nesidiocoris tenuis (Heteroptera: Miridae) on Tomato Yield. J Econ Entomol 101:1864-1870. https://doi.org/10.1603/00220493-101.6.1864

Sanchez JA, Cassis G (2018) Towards solving the taxonomic impasse of the biocontrol plant bug subgenus Dicyphus (Dicyphus) (Insecta: Heteroptera: Miridae) using molecular, morphometric and morphological partitions. Zool J Linn Soc 184:330-406. https://doi.org/10.1093/zoolinnean/zly005

Sanchez JA, del Amor FM, Flores P, López-Gallego E (2016) Nutritional variations at Nesidiocoris tenuis feeding sites and reciprocal interactions between the mirid and tomato plants. J Appl Entomol 140:161-173. https://doi.org/10.1111/jen.12246

Sonneveld C, Voogt W (2009) Nutrient solutions for soilless cultures. Plant Nutrition of Greenhouse crops. Springer, Netherlands, Dordrecht, pp 257-277

Tommasini MG, Burgio G, Mazzoni F, Maini S (2002) On intra-guild predation and cannibalism in Orius insidiosus and Orius laevigatus (Rhynchota Anthocoridae): Laboratory experiments. Bull Insectology 55:49-54

Trottin-Caudal Y, Chabrière C, Fournier C et al (2006) Current situation of Bemisia tabaci in protected vegetables crops in the South of France. IOBC/WPRS Bull 29:53-58

van Lenteren JC (2012) The state of commercial augmentative biological control: Plenty of natural enemies, but a frustrating lack of uptake. Biocontrol 57:1-20. https://doi.org/10.1007/ s10526-011-9395-1

Wheeler AG (2001) Biology of the plant bugs (Hemiptera: Miridae): pests, predators, opportunists. Comstock Publishing Associates, Ithaca

Wheeler AG, Krimmel BA (2015) Mirid (Hemiptera: Heteroptera) specialists of sticky plants: adaptations, interactions, and ecological implications. Annu Rev Entomol 60:393-414. https://doi.org/10. 1146/annurev-ento-010814-020932

Publisher's Note Springer Nature remains neutral with regard to jurisdictional claims in published maps and institutional affiliations. 